\title{
Quantification of potential recruitment of large woody debris in mountain catchments considering the effects of vegetation on hydraulic and geotechnical bank erosion and shallow landslides
}

\author{
Eric Gasser ${ }^{1,2}$, Andrew Simon ${ }^{3}$, Paolo Perona ${ }^{4}$, Luuk Dorren ${ }^{1,2}$, Johannes Hübl ${ }^{2}$, and \\ Massimiliano Schwarz ${ }^{1}$ \\ ${ }^{1}$ Bern University of Applied Sciences (BFH), School of Agricultural, Forest and Food Sciences \\ (HAFL), Laenggasse 85, 3052 Zollikofen, Switzerland \\ ${ }^{2}$ University of Natural Resources and Life Sciences Vienna (BOKU), Peter-Jordan-Strasse 82, 1190 \\ Vienna, Austria \\ ${ }^{3}$ Cardno, P.O. Box 1236, Oxford, 38655 Mississippi, United States of America \\ ${ }^{4}$ The University of Edinburgh, Mayfield Road, Edinburgh EH9 3JL, Scotland
}

\begin{abstract}
Large woody debris (LWD) exacerbates flood damages near civil structures and in urbanized areas and the awareness of LWD as a risk is becoming more and more relevant. The recruitment of "fresh" large woody debris has been documented to play a significant role of the total amount of wood transported during flood events in mountain catchments. Predominately, LWD recruitment due to hydraulic and geotechnical bank erosion and shallow landslides contribute to high volumes of wood during floods. Quantifying the effects of vegetation on channel and slope processes is extremely complex. This manuscript therefore presents the concepts that are being implemented in a new modelling framework that aims to improve the quantification of vegetation effects on LWD recruitment processes. One of the focuses of the model framework is the implementation of the effect of spatio-temporal distribution of root reinforcement in recruitment processes such as bank erosion and shallow landslides in mountain catchments. Further, spatio-temporal precipitation patterns will be considered using a probabilistic approach to account for the spatio-temporal precipitation variability to estimate a LWD recruitment correction coefficient. Preliminary results are herein presented and discussed in form of a case study in the Swiss Prealps.
\end{abstract}

\section{Introduction}

Large woody debris (LWD), also known as coarse woody debris, in-stream wood, drift wood or large wood, is acknowledged to have important ecological functions and plays a significant role in river morphology, but it also exacerbates flood damages near civil structures and in urbanized areas (e.g., [1-4]). The recruitment of "fresh" large woody 
debris has been documented to be a key component of the total amount of wood transported during floods in mountain catchments, particularly because of streambank erosion, streambank failure and shallow landslides (e.g., [5-10]). The term 'recruitment' hereby refers to all processes involved in delivering woody material into water bodies through hydromorphodynamic or gravitational processes at any time (e.g., [11-13]); 'hydraulic bank erosion' is the result of flowing water applying hydrodynamic forces onto the streambank [14] removing sediment from the streambank [14-16]; and 'geotechnical bank erosion' is the failing of streambanks under gravity $[14,17]$.

Although numerous studies have quantified the stabilizing effects of vegetation for bank and hillslope processes (e.g., [18-28]), few studies incorporate the spatial distribution of mechanical and/or hydrological effects of vegetation influencing LWD recruitment. The objective of this manuscript is to present a new model framework that aims to consider the effects of the spatio-temporal distribution of vegetation on hydraulic and geotechnical bank erosion (BankforMAP) and shallow landslides (SlideforMAP, [25-27]) in mountain catchments.

\section{Materials and methods}

\subsection{Model framework}

Hydraulic and geotechnical bank erosion is modeled in BankforMAP, where erosion and subsequent LWD recruitment scenarios based on hydraulic geometry relations [29-32], physical parameters (i.e., material properties) and probability are considered. Hydraulic geometry are power functions reflecting the change of width, mean depth and velocity with increasing discharge at a given cross section. It further also emphasizes the importance of the amount and size of sediment, roughness and channel slope, or gradient. Based on the principles of hydraulic geometry, it is feasible to find relations between governing processes and geometric parameters influencing recruitment and mobilization of LWD. The material properties are calculated applying the bank surface toe erosion model BSTEM [3335], where a matrix of numerical experiments is set up to calculate important processesbased parameters to represent a range of possible conditions in the channel network. The results then represent potential areas along the channel where possible scenarios can lead to erosion and LWD recruitment.

Potential shallow landslide occurrences are modeled using the existing model SlideforMAP: SlideforMAP is a spatially explicit model that calculates the probability of shallow landslides occurring on a slope considering the mechanical effects of vegetation per scenario (i.e., root reinforcement). In both BankforMAP and SlideforMAP, the effects of vegetation are implemented by using tree detection algorithms: The algorithm FINT [3536] detects the position of treetops and extrapolates tree dimensions (tree height and diameter on breast height). This information is used to incorporate the location and dimension of trees to further implement root reinforcement.

To account for natural heterogeneity of precipitation, a stochastic approach is being implemented: Spatio-temporal precipitation patterns are difficult to model due to their complex nature. In accord to [38], we intend on using probability distribution functions to account for the incomplete knowledge of data available for precipitation estimations. The spatio-temporal precipitation pattern is then used to estimate a correction coefficient to give a more robust estimation on LWD recruitment volumes. 

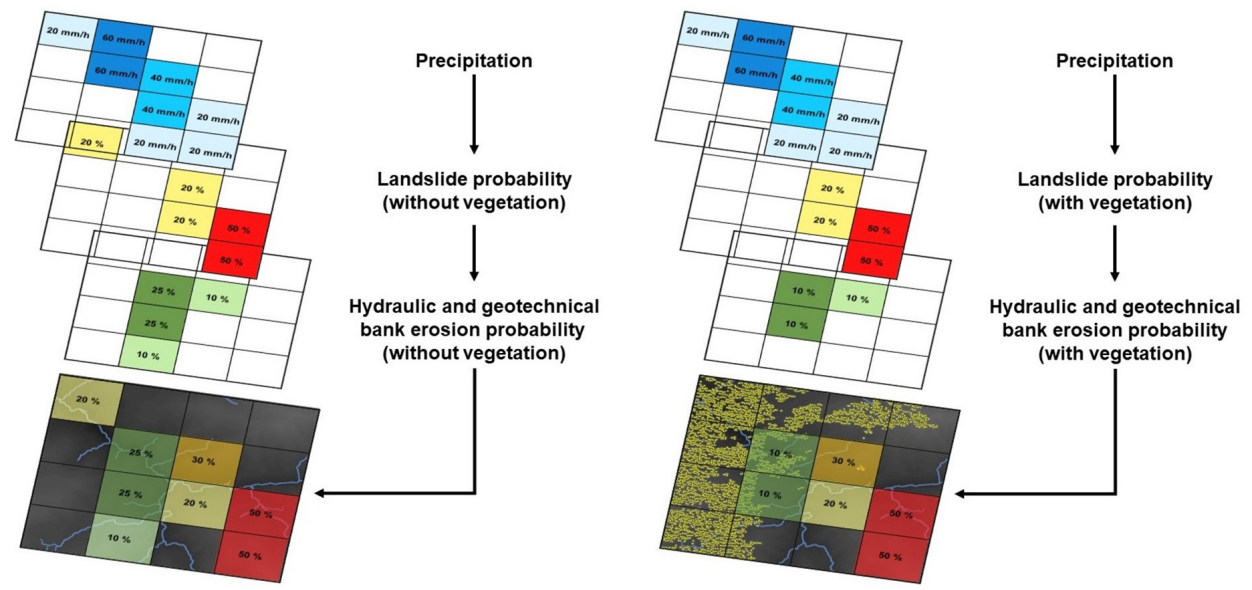

Fig. 1. Idealized schematic of the overlapping scenario-based results from BankforMAP and SlideforMAP. Left without and right considering the effects of vegetation. The blue cells represent spatio-temporal precipitation variabilities, and the yellow, red, light and dark green cells represent modelled spatio-temporal process probabilities.

Finally, the overlapping of scenario-based results from BankforMAP and SlideforMAP generate a probability matrix with potential LWD recruitment volumes explicitly considering spatial structures of forests and the effect of root reinforcement. This probability matrix visualizes conceptually the probability of hydraulic and geotechnical bank erosion, as well as shallow landslides contributing to LWD recruitment in mountain catchments (fig. 1). The spatio-temporal precipitation variability will be used to calculate a correction factor thus the magnitude of the processes is precipitation dependent.

\subsection{Site description of the case study}

The preliminary results are discussed in the context of a case study in the Swiss Prealps: The Zulg is a mountain stream with a catchment area of approximately $89 \mathrm{~km}^{2}$ and a length of approximately $23 \mathrm{~km}$. It merges into the Aare River northwest of the city Thun at $46^{\circ} 46^{\prime} 28^{\prime \prime} \mathrm{N}$ and $7^{\circ} 36^{\prime} 13$ ' $\mathrm{E}$ (fig. 2). The modeled results are compared with case studies and event history analyses.
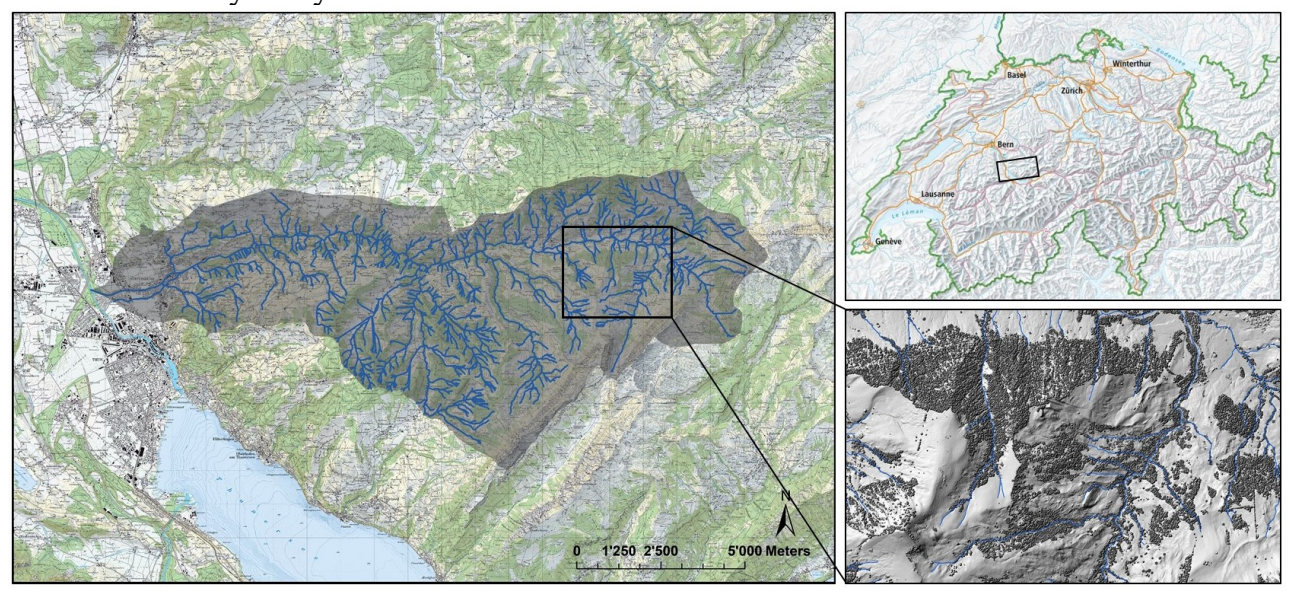

Fig. 2. Zulg catchment in the Bernese Alps (left), general map of Switzerland (upper right) and the zoom for the case study in the "Sulzigraben" (lower right). Source: Swisstopo. 
The spatial distribution of shallow landslide probabilities is modeled using SlideforMAP for the Sulzigraben, a tributary merging into the Zulg by Innereriz at $46^{\circ} 47^{\prime} 10^{\prime \prime} \mathrm{N}$ and $7^{\circ} 49^{\prime} 21^{\prime}$ "E, during a precipitation event with a return period of 100 years (fig. 3). In SlideforMAP, shallow landslide probabilities can be estimated considering root reinforcement (with vegetation) or without consideration of root reinforcement (no vegetation). The position of the treetops (yellow points) were modeled with FINT. To consider the trees that are affected by landslides, only trees within 80 meters from the channel network were selected that lie within the area of probable shallow landslide occurrences. The buffer of 80 meters was chosen, because SlideforMAP does not contain a runout model yet.
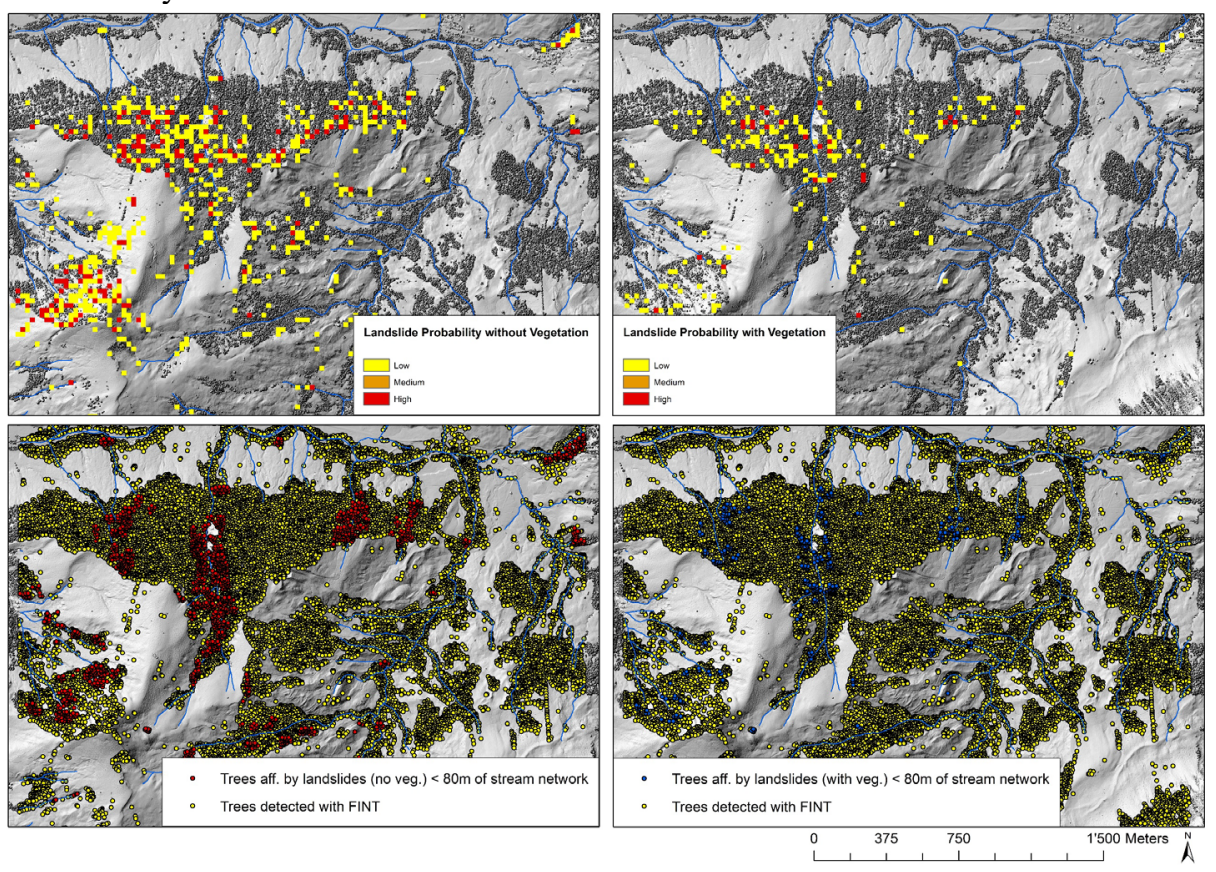

Fig. 3. Shallow landslide probabilities modeled with SlideforMAP. Shallow landslide probability with no vegetation (no root reinforcement), shallow landslide probability with vegetation (root reinforcement), trees detected with FINT incl. trees detected within the area of probable landslides (no vegetation) and $80 \mathrm{~m}$ of the channel network, and trees detected with FINT incl. trees detected within the area of probable landslides (with vegetation) and a distance of $80 \mathrm{~m}$ of the channel network (from upper left to lower right). The background map is a LiDAR derived digital surface model from swisstopo.

\section{Results}

Our preliminary results present potential LWD recruitment from shallow landslides. Based on our analysis, potential LWD recruitment without considering root reinforcement in SlideforMAP would result in 1882 trees, or approximately $13^{\prime} 600 \mathrm{~m}^{3}$ of wood recruited (table 1). Potential LWD recruitment considering root reinforcement in SlideforMAP would result in 395 trees (79\% lesser trees), or approximately 9' $400 \mathrm{~m}^{3}$ of wood recruited (31\% lesser wood). Compared to a recent study [39] that investigated potential LWD recruitment for the Sulzigraben, $17^{\prime} 640 \mathrm{~m}^{3}$ wood was estimated considering shallow landsides and geotechnical bank erosion. A correction coefficient was however not applied to consider spatio-temporal precipitation events and our preliminary analysis were not validated in the field yet. 
Table 1. Potential LWD recruitment volumes based on three different approaches.

\begin{tabular}{|c|c|c|c|}
\hline & $\begin{array}{c}\text { SlideforMAP without } \\
\text { vegetation }\end{array}$ & $\begin{array}{c}\text { SlideforMAP with } \\
\text { vegetation (present } \\
\text { condition) }\end{array}$ & $\begin{array}{c}\text { Case study } \\
\text { (shallow } \\
\text { landslides and } \\
\text { geotechnical } \\
\text { bank erosion) }\end{array}$ \\
\hline $\begin{array}{c}\text { Potential LWD } \\
\text { recruitment volume } \\
{\left[\mathbf{m}^{3}\right]}\end{array}$ & $13^{\prime}$ '600 & $9{ }^{\prime} 400$ & $17^{\prime} 640$ \\
\hline
\end{tabular}

\section{Discussion and outlook}

Although LWD research has arisen over the last few decades, quantifying the role of vegetation on channel and slope processes is extremely complex owing to differences in species characteristics and has often been over generalized so far. Our model framework incorporates physical laws and probability to estimate potential LWD recruitment scenarios considering the effect of vegetation. The advantage of the proposed framework is that it allows to localize areas where vegetation (particularly trees) can increase slope and bank stability, giving detailed information to stakeholders where to focus their efforts in forest management.

As the preliminary results show, shallow landslide probabilities account for spatiotemporal heterogeneities and areas where potential LWD recruitment occurs can be investigated to mitigate the risk. Randomly scattered precipitation with randomly generated intensities based on observations can further generate numerous possible scenarios that affect the triggering of e.g. shallow landslides or peak discharge events affecting hydraulic and geotechnical bank erosion. This allows us to "correct" the potential LWD recruitment volumes by including a correction factor. The inclusion of a correction factor has however not been implemented yet and its implementation is in the development phase.

The results from SlideforMAP hence need to be modeled considering spatio-temporal precipitation patterns to include a correction coefficient. Further, only trees within 80 meters from the channel network were selected because landslide runout is not considered in the model yet. A runout model will also be implemented in the near future. BankforMAP and precipitation probabilities need to be adapted and refined. Further, the model framework needs to be validated in the field as well as tested and applied in other (sub-) catchments.

\section{References}

1. H. Piégay, A. Thevenet, A. Citterio, Catena 35, 1, 19-39 (1999).

2. N.S. Lassettre, G.M. Kondolf, River Research and Applications 28, 1477-1487 (2012).

3. S.V. Gregory, K.L. Boyer, A. M. Gurnell (Eds.), The Ecology and Management of Wood in World Rivers, Am. Fish. Soc. Symp. 37 (2003).

4. E. Wohl, D.N. Scott, Earth Surf. Processes Landforms 42, 5-23 (2017).

5. G.R. Bezzola, C. Hegg (Eds.), Ereignisanalyse Hochwasser 2005. Teil 1 Prozesse, Schäden und erste Einordnung, Umwelt-Wissen 0707, 1-215 (2007).

6. P. Waldner, D. Köchli, T. Usbeck, L. Schmocker, F. Sutter, C. Rickli, D. Rickenmann, D. Lange, N. Hilker, A. Wirsch, R. Siegrist, C. Hug, M. Kaennel, Schwemmholz des Hochwassers 2005 - Schlussbericht des WSL-Teilprojekts Schwemmholz der Ereignisanalyse BAFU/WSL des Hochwassers 2005. Swiss 
Federal Research Institute for Forest, Snow and Landscape Research WSL, Birmensdorf, 1-66 (2007).

7. A. Lucìa, F. Comiti, M. Borga, M. Cavalli, L. Marchi, NHESS 15, 1741-1755 (2015).

8. F. Comiti, A. Lucìa, D. Rickenmann, Geomorphology 269, 23-39 (2016).

9. N. Steeb, D. Rickenmann, A. Badoux, C. Rickli, P. Waldner, Geomorphology 279, 112-127 (2017).

10. F. Nakamura, J.I. Seo, T. Aksaka, F.J. Swanson, Geomorphology 279, 176-187 (2017).

11. P.W. Downs, A. Simon, Geomorphology 37, 65-91 (2001).

12. D.J. Martin, L.E. Benda, Transactions of the American Fisheries Society 130, 940958 (2001).

13. L.E. Benda, J. C. Sias, Forest Ecology Management 172, 1-16 (2003).

14. P.Y. Julien, River mechanics (2002).

15. C.R. Thorne, Gravel-Bed Rivers, 227-271 (1982).

16. P.J. Julian, R. Torres, Geomorphology 76, 193-206 (2006).

17. C.R. Thorne, J.B. Murphey, W.C. Little, USDA Sedimentation Laboratory Oxford, Mississippi (1981).

18. L.J. Waldron, SSSA 41, 843-849 (1977).

19. T.H. Wu, W.P. McKinnell, D.N. Swanston, CGJ 16, 19-33 (1979).

20. V.J. Terwilliger, L.J. Waldron, GSA 103, 775-785 (1991).

21. A. Burton, J.C. Bathurst, Environmental Geology 35, 89-99 (1988).

22. J.R. Greenwood, J.E. Norris, J. Wint, Proceedings of the ICE-Geotechnical Engineering 157, 199-207 (2004).

23. N. Pollen, A. Simon, A. Collison, Riparian vegetation and fluvial geomorphology 8, 125-139 (2004).

24. N. Pollen-Bankhead, A. Simon, Geomorphology 116, 353-362 (2010).

25. M. Schwarz, P. Lehman, D. Or, ESPL 35, 354-367 (2010).

26. M. Schwarz, D. Cohen, D. Or, Geomorphology 171-172, 190-200 (2012)

27. M. Schwarz, A. Rist, D. Cohen, F. Giadrossich, P. Egorov, D. Büttner, M. Stolz, J.J. Thormann, JGR: Earth Surface 120, 2103-2120 (2015).

28. D. Cohen, M. Schwarz, Earth Surface Dynamics Discussions. https://doi.org/10.5194/esurf-2017-10 (2017).

29. L.B. Leopold, T. Maddock, The hydraulic geometry of stream channels and some physiographic implications 252 (1953).

30. J. T. Hack, Studies of longitudinal stream profiles in Virginia and Maryland 294, 1-97 (1957).

31. L.B. Leopold, M.G. Wolman, P. Miller, Fluvial processes in geomorphology (1964).

32. A. Vianello, V. D'Agostino, Geomorphology 83, 266-281 (2007).

33. A. Simon, A. Curini, S.E. Darby, E.J. Langendoen, Geomorphology 35, 193-217 (2000).

34. A. Simon, A.J.C. Collison, ESPL 27, 527-456 (2002).

35. N. Pollen-Bankhead, A. Simon, ESPL 34, 471-480 (2009)

36. L. Dorren, User manual, 1-6 (2017)

37. J. Menk, L. Dorren, J. Heinzel, M. Marty, M. Huber, Schweizerische Zeitschrift für Forstwesen 168, 151-159 (2017).

38. L. Benoit, G. Mariethoz, D. Allard, EGU General Assembly Conference Abstracts 19, 9169 (2017).

39. G. Hunziker, Schwemmholz Zulg. Untersuchungen zum Schwemmholzaufkommen in der Zulg und deren Seitenbächen, 1-51 (2017). 